This is an author produced version of a paper published in Sustainability Science.

This paper has been peer-reviewed but may not include the final publisher proof-corrections or pagination.

Citation for the published paper:

Lotten Westberg and Merritt Polk. (2016) The role of learning in transdisciplinary research: moving from a normative concept to an analytical tool through a practice-based approach. Sustainability Science. Volume: 11, Number: 3, pp 385-397.

http://dx.doi.org/10.1007/s1 1625-016-0358-4.

Access to the published version may require journal subscription.

Published with permission from: Springer.

Standard set statement from the publisher:

The final publication is available at Springer via http://dx.doi.org/ 10.1007/s11625-0160358-4

Epsilon Open Archive http://epsilon.slu.se 


\title{
The role of learning in transdisciplinary research: Moving from a normative concept to an analytical tool through a practice-based approach
}

\author{
Lotten Westberg and Merritt Polk \\ Accepted version, Submitted to Sustainability Science, February 2016
}

\begin{abstract}
Transdisciplinary (TD) research is an example of a participatory research approach that has been developed to address the complexity of societal problems through the exchange of knowledge and expertise across diverse groups of societal actors. The concept of knowledge exchange is central to the ability of TD research to produce usable knowledge. There is, however, limited theoretical attention to the processes that enable knowledge exchange, namely learning. In this article we analyze the "transferability" of knowledge generated in TD research settings from a practice-based approach. In this approach, learning and knowing are seen as situated in social practices, in meaning making processes where the involved participants make sense of what they do and why they do it. We describe and analyze three TD projects, and discuss the role of practitioners' perspectives in the interpretation of the tasks and realization of TD, and in the consequences this has for the organization of the research process and the usability of its results. The analysis shows that while the project teams were given the same task and framework, they did not understand or enact TD in a similar fashion. The three projects created different goals and organizations. They also resulted in different challenges, which could be identified and analyzed by the use of a practice-based approach to learning. In the conclusions, we identify aspects for both practice and research that are important for creating sufficient conditions for learning in TD research processes so that they can better promote contributions to societal change.
\end{abstract}

Key words: transdisciplinary research, situated learning, sociocultural theory, sustainability

\section{Introduction}

Transdisciplinary (TD) research has been developed to address complex societal problems through the involvement of both multiple disciplines and a diversity of societal actors in research situated in reallife contexts. The goals of TD research are to create outcomes that are both scientifically rigorous and socially robust (Nowotny et al 2001, Pohl and Hirsch Hadorn 2007, Scholz and Steiner 2015a, Wiek et al 2012). The ability of TD research to reach such goals rests on the assumption that creating effective and legitimate solutions to complex societal problems requires sharing and exchange of knowledge and experiences among a diversity of disciplines and work practices (Gibbons et al 1994, Lang et al 2012, Nowotny et al 2001, Polk 2014, Robinson 2008). While there is much emphasis on dialogue and participation in the TD discourse, as well as on frameworks and methods for promoting them (Bergmann et al 2012, Pohl and Hirsch Hadorn 2007, Scholz and Steiner 2015b), there is little theoretical attention directed at what happens within such activities, at the mechanisms underlying how knowledge exchange occur in practice. The aim of this article is to contribute to increasing our understanding of the processes that underlie the promotion and creation of socially robust knowledge by applying a practice based theory to learning and knowing to TD research. We argue how such approaches to learning can give better analytical tools for understanding what happens between researchers and practitioners in TD research projects. ${ }^{1}$ We focus on learning as a situated activity, an

\footnotetext{
${ }^{1}$ The terms 'practitioner', 'user', and 'policy' are used to refer to individuals and activities that fall within the professional mandates of public and private spheres of activity. This includes employees from public bodies such as any municipal and regional officials, planners and administrators as well as business and community group representatives and the general public.
} 
integral and inseparable aspect of the social practices in which individuals participate and, through their participation, contribute to the development of situated knowledge, competences and identities. The theory of situated learning was originally developed by Lave and Wenger (1991). It transformed the assumptions that guide studies of learning and knowing, influenced a number of disciplines and opened up new areas of research (Contu 2014, Gherardi 2001, Hughes et al 2007, Nicolini et al 2003). We use this theory to better understand how learning processes affect the ability of research to contribute to societal change processes.

This article applies a situated learning perspective to TD research (Hotho et al 2014, Chaiklin \& Lave 1993, Lave \& Wenger 1991). While this view on learning is not used in the TD discourse, learning is used in a variety of ways. ${ }^{2}$ Social, societal, mutual, collective, transformative, sustainability and transdisciplinary learning are used by scholars to refer to societal goals, important research areas, as well as methods or means for achieving sustainability (Kates et al 2005, Miller et al 2014, Pohl et al 2010, Popa et al 2015, Whittmayer and Schäpke 2014, Scholz \& Steiner 2015a, b; Wiek et al 2011). In Kates et al, social learning is seen as necessary to navigate transitions to sustainability, in terms of both managing risks and uncertainties, and in terms of the need for integrating knowledge and expertise from diverse stakeholders (Kates et al 2005). In an article from 2014, a group of researchers from the US, Canada, Sweden and the Netherlands formulated a solution oriented research agenda for sustainability science, where social and institutional learning is included as one of the core research pathways needed to strengthen the discipline and increase its ability to contribute to societal transitions to sustainability (Miller et al 2014: 243). In other examples, learning is seen as a means or method for TD research itself, such as its use in transformative and sustainability learning (Scholz \& Steiner 2015ab, Wiek et al 2011). Learning is also highlighted as essential in the promotion of skills needed for facilitating collective learning processes to enhance the creation of thought collectives across diverse participant groups (Pohl et al 2010).

All of the above approaches share a normative and/or instrumental use of the concept of learning. Learning is emphasized as a research method, as a means to other ends (capacity building, knowledge integration, adaptive management), as well as a goal in itself. The conceptualization of learning as a normative goal or method, make it impossible to uncover and evaluate what learning entails, how it occurs in different types of practice, or how it can specifically contribute to sustainable development. This creates substantial barriers to both the empirical mapping and theoretical development of learning in the context of TD research. An exception to this lack of theoretical attention to learning can be found in a recent article from Futures, where Schauppenlehner-Kloyber and Penker (2015) focus on the group dynamics that underlie social learning and capacity building in TD research (Schauppenlehner-Kloyber and Penker 2015: 58). They point out, that while there is a great deal of attention given to frameworks, research design, and facilitation skills in TD research, there is little attention to the mechanics behind learning and what this entails in TD processes. While their aim is similar to the present article, namely to better understand learning processes in TD research, their approach focuses on theories on group dynamics, where learning is still used as a normative method and goal within group processes. Another exception can be found in Pohl et al. 2010, where, while they do not focus on learning per se, their use and discussion of 'thought collectives' and 'thought styles' within the TD research context capture the focus of this article.

Given the importance of learning for the TD discourse, and its almost exclusively normative and instrumental use, we think that Sustainability Science, a journal that publishes cutting edge TD

\footnotetext{
${ }^{2}$ This does not include the discourse on education in sustainability science.
} 
research, could benefit from an in-depth analysis of learning and its role in TD research. As a starting point for this, we outline and test a view of learning as situated (Contu \& Willmot 2003, Hotho et al 2014, Lave \& Wenger 1991, Nicolini et al 2003, Wenger 1998). This practice-based approach to learning as a situated activity is helpful when aiming to understand how meaning and knowing are created within TD research projects, and the implications this has for the ability of those involved to contribute to societal change processes. Our work builds upon the original theory of situated learning (Lave \& Wenger 1991), critique and development of this theory in recent decades (Hughes et al 2007, Nicolini et al 2003), as well as other practice based approaches (cf Engeström \& Middleton 1996, Nicolini 2012).

Based on a view of learning as situated in social practices, TD research projects is seen as an example of a temporary, boundary practice that is co-constructed by diverse societal actors when they cooperate and exchange experiences to understand and solve societal problems. The knowledge development taking place in these practices is situated, in the sense that it is meaningful and relevant for the actors in relation to how they collectively create meaning regarding what their practice should accomplish and why (Carlile 2002, Heizmann 2011, Gherardi 2001, Gherardi \& Nicolini 2003). From the perspective of TD research, the logic behind this approach is that knowledge production will lead to the development of, for the participants, meaningful shared knowledge and outcomes with substantial implications for their ordinary practices. Thus the inclusion of stakeholders in the process should result in an increased ability to impact societal changes processes. However, the theory of situated learning is not normative. It does not imply that learning necessarily leads to more socially robust or usable outcomes. It instead focuses on the processes though which meanings are continuously created and re-created in the social practices where individuals participate. It can therefore be used to uncover and understand why TD research practices evolve as they do, how different actors influence the construction of such practices, including the meaning of what they are there to do and why, and consequently help us to better understand the knowledge production that is taking place. Situated learning theory helps to problematize the significance knowing and knowledge can have both inside and outside of TD research, that is, for both the TD project processes and for the actors' ordinary practices.

This paper analyzes three TD research projects that include both researchers and practitioners from different disciplines and sectors. Since one of the important purposes of TD research is to integrate non-scientific expertise in research, we focus on the role of practitioners' perspectives in the creation of these projects. We also focus on the consequences this has for the project's organization and outputs, as well as on how the practitioner's look upon and value the project outcomes - a question that is frequently discussed in TD literature (Hellström 2015, Jahn \& Keil 2015, Wittmayer \& Schäpke 2014, Wiek et al 2014).

\section{Theoretical framework}

The theory of situated learning applied in this paper views learning as a social activity. In this theory, meanings of the world are socially constructed and situated in the social practices in which individuals partake. The meanings of what members of a social practice do are created while the doing is going on, that is, in the continuous process of interaction maintained by the members as they organize their activities to accomplish what the practice, according to them, is meant to accomplish (Lave \& Wenger 1991, Wertsch 1991,Yanow 2003). Learning is understood as the co-creation of meaning and knowing through social interactions. The idea of learning as situated thus emphasizes the relational character and interdependency of individuals, activities, context, meaning creation, and knowing (Lave \& Wenger 1991:50). Here, participation in social practice is the foundation of learning. While keeping 
their practices going (that is, participating), members learn. Acting and learning are thus inseparable, as they are taking place simultaneously (Gherardi 2001, Lave \& Wenger 1991, Nicolini et al 2003).

Originally, the theory of situated learning was applied in studies focusing on rather stable and permanent work practices (Chaiklin \& Lave 1993, Hughes 2007, Lave and Wenger 1991). The aim was to show that learning is a social rather than individual endeavor, and that learning through participation creates knowledgeable situated identities of the members as they maintain their work practice. This theory suggests that meanings of actions, skills and knowledge created in one practice cannot be "transferred" to another, as they are given different (if any) meanings when introduced to different practices (Gherardi 2001, Gherardi \& Nicolini 2003). This approach has inspired management and organization researchers who question if and how knowledge and insights developed in temporary projects consisting of representatives from different divisions of (or between) companies and created solely to contribute to innovations and problem solving in their ordinary divisions, can actually be of use and benefit in other contexts (Bechky 2003, Brown \& Duguid 2001, Carlile 2002, Contu 2014, Contu \& Willmott 2003, Heizmann 2011, Swan et al 2010). Given that similar types of questions are asked by TD researchers, regarding socially robust and actionable knowledge, organization and management studies may be able to throw new theoretical light over some of the challenges that the TD research faces.

According to a situated learning approach, members of a practice co-create the meaning they give to their tasks, depending on the participants, conditions and resources available to them. In a sense, practices can be seen as living a life of their own. Therefore the creation of a practice can never be fully controlled from outside, implying that instructions and missions given to a practice, cannot be expected to be interpreted and fulfilled the way intended by those formulating them (Nicolini et al 2003, Wenger 1998, Westberg \& Powell 2015). This suggests, when studying learning from a situated learning approach, it is important to analyze how the members of the TD practices themselves interpret what they are meant to accomplish (Yanow 2003). How does the meaning the members give to their mission guide their understanding of what they need to know, do and learn to accomplish their goals?

According to Bechky (2003), knowledge transformation between practices is possible if the members of a temporary practice manage to bring their different context dependent perspectives into attention and consciously explore the sum of their joint knowledge, beliefs and suppositions. This means that for TD practices to be successful in the ambition of knowledge sharing and joint knowledge production, the members have to create spaces for reflection and create opportunities for learning on a meta-level. In other words, in order for knowledge sharing and joint knowledge production to take place, the TD practices need to be organized in a way that enables the members to perceive their ordinary work practices respectively from a distance, to acknowledge the limitations and possibilities of the thought worlds developed there, compare them with other thought worlds represented in the group, and place them in relation to a wider context (Pohl et al 2010). This "knowledge transformation" needs to go in the other direction as well. The members need to reflect upon how the knowledge and insights jointly generated in the TD practices fit and can benefit their ordinary work practices. Self-reflection and meta-learning are thus crucial components in enabling the co-production of meaning and knowing across diverse sectors and mandates. Given the overall aim of TD research to produce socially robust results, this suggests that a second important area of analysis is if/how what the actors learn by being member's of a temporary TD practice is meaningful and relevant to them in their ordinary work practices. 
In formulating our research questions from the theoretical approach outlined above, we start from the assumption that the three TD groups under study represent temporary practices, which the members co-create, based on how they interpret the meanings of the instructions given to them. The learning and knowledge created, make sense in these temporary practices, but are not necessarily meaningful outside of these contexts. We assume that for learning to take place in TD practices, spaces for metalearning or reflection are necessary. Our research questions are the following:

1 In what ways did the project members interpret their task of TD research and what were the consequences for the organization and realization of the project?

2. In what ways did the project enable the practitioners to reflect upon the problem focus and results in relation to their own ordinary practices?

\section{Case study and method}

The projects that form the empirical basis for this article where part of a Center for transdisciplinary research in a City in Sweden. This TD Platform (as we chose to call it here) was established and funded by seven partners, three from research and four from the public bodies. These included two Universities in the City, in cooperation with a Research Institute, as well as a number of prominent public authorities and associations of the region in which the City is located including the Central City Office, the Region Association of Local Authorities (RALA), the Regional Political Body (RPB), and the Regional branch of the Federal Government (RFG). The three projects we describe here were among the first projects on the TD Platform and they originated from ideas initiated by the partners of the TD Platform.

Data was collected on these projects through a number of methods. These included interviews with the project leaders and working groups, a monthly project leadership meeting, and participatory observation of select project activities. There were five rounds of interviews with the projects leaders, throughout the process, and one with the working groups at the end, a total of six rounds. To increase reliability, an external evaluator conducted the final round with the project leaders for each project. A total of 32 interviews were recorded and transcribed. The interviews were semi-structured and included questions in four main areas: the inclusion of relevant stakeholders and researchers, methods and degree of collaboration, knowledge integration, and usability for both practice and research. The questions were formulated to promote reflexivity among the participants regarding the creation of joint processes, and included overall experiences, decision-making and specific tensions in each respective area. Following Crang \& Cook (2007), all of this material (interviews, meetings, participatory observations of the projects and project results), were interpreted, coded and thematically categorized in relation to the two research questions outlined above.

\section{Case descriptions and analysis}

This section starts by listing the conditions under which the projects occurred. Following this we give a description of each project. These descriptions highlight some events, while a number of others, which we believe are less relevant for this article, are not mentioned. Someone who is familiar with the projects might think that we do not do them justice. This is not our intention. Our intention is to describe the parts of the projects that are relevant from a situated learning perspective.

The projects ran for approximately 15 months. TD platform staff coordinated these projects through a set of guidelines and instructions for promoting TD knowledge co-production (Polk 2015). These instructions included that:

1. Every project should be co-lead by a researcher and a practitioner. 
2. Every project team should include a necessary diversity of expertise from both the researcher and public bodies.

3. The project group members should jointly formulate the research problems and project design, and jointly carry out the execution of the project, its' data collection, analysis and production of results.

4. All of the involved practitioners, like the researchers, should be paid for their time through cash or in-kind contributions from the TD platform or partners.

5. The projects were required to generate two types of results: a policy report, which could be used by the practitioners in their practice, and scientific results in peer reviewed articles, teaching, and conference presentations.

\section{Project A - A project characterized by efficiency and quality}

Project A focused on adaptation to climate change. The research area was a district located in the central City area that was at grave risk for sea level rise. A practitioner, responsible for the comprehensive plan and the long-term land use strategy at the City Planning Authority, introduced the idea. She had recently encountered a scenario model, illustrating the effects of three strategies that could be used in climate adaptation development processes. She saw an opportunity to use this TD project to test the possibilities of combining the scenario model with a sustainable development analysis - a social, economic and environmental assessment of climate change responses in urban planning (hereafter called the "SD-model"). The project idea was accepted by the TD platform. The practitioner behind it was selected as one of the project leaders (P1). A senior advisor in climate and energy projects at the Research Institute was selected as the other project leader (R1).

Both of the project leaders prioritized effective management in their project leadership. This included clear structure, deadlines and a tight project team. Since the project leader from the research institute (R1) saw herself more as an experienced advisor (that is, a practitioner) than as a researcher, the project leaders decided it was enough to include only one more practitioner, $\mathrm{P} 2$, who also came from the City Planning Authority. The spread of subject areas among the three researchers invited to the team included a professor in civil and environmental engineering (R2) and an interdisciplinary researcher from the City Universities (R3), and a social scientist from the Research Institute (R4).

At the two-day project kickoff, the project leaders presented a complete project idea that was used as a starting point to jointly discuss and design the project. According to the interviews, the kickoff was characterized by constructive discussions that resulted in everyone accepting the project idea and schedule. Based on the idea that clarity was needed to avoid misunderstandings later on, questions on how to define and ensure a TD approach were discussed in detail. The agreed upon TD "definition" emphasized the importance of achieving high quality and relevant results for both science and practice. To achieve the goal of effectiveness, and simultaneously meet these TD requirements, the team decided to organize the project into two parallel parts, one with relevance for practice and one with relevance for research. The idea was to make two separate, but joint, analyses based on the same empirical material. The practitioner report would be designed to contribute to creating a more complex tool for integrating sustainable development and climate change strategies in urban planning (the 'SD model' suggested by P1). Contributions to research were more open and focused on exploring the interactions between practitioners and researchers and would result in scientific articles. R2 and R3 note that it was thanks to the in-depth discussions that took place during the kick-off, that they were able to jointly design the research orientation of the work, which increased their commitment to the project. 
The empirical part of the project was based on three half day workshops including in total around 70 invited researchers and practitioners who were active in city planning, policy-making and implementation. The project group together identified the invited stakeholders, formulated the interview questions, and carried out the workshops. During these workshops, the invited participants were divided into smaller cross sector focus groups. Based on illustrations of the scenarios for climate change adaptation, they discussed the outcomes of climate change adaptation strategies in urban planning in relation to the social, economic and environmental aspects of sustainable development. All of the workshops were recorded and transcribed.

During the kickoff, the project group agreed that everyone would work together in completing both the scientific article and practical report, in line with their TD approach. However, when it was time to start processing the data, R2 took the lead in analyzing the 400 pages of transcriptions from the workshops and for compiling the first scientific analysis. The focus ended up being on different approaches to climate adaptation and sustainable urban development that were evident in the material. Based on this, R2 took the initiative for an article. Different versions of this article were circulated and discussed throughout the project team via email and phone. Since P1 received demanding new work responsibilities during the project time, and $\mathrm{P} 2$ had to limit his participation in the project because of family obligations, it was primarily R3 and R4 who assisted R2 on the article. Because of the problems noted above, R1 delegated the analysis and completion of the practitioner report to a new employee at the Research Institute. In the interviews, the project members noted that they didn't discuss or refer to this new division of labor; it 'just happened'.

To get feedback on the results of the project, both the scientific article and the practitioner report were presented at a seminar for the platform partners and focus group participants. The seminar participants showed great interest in the scientific article, while the practical report received an equal amount of criticism. The work with completing the practical report was handed over to an external consultant who was asked to make it more relevant for practitioners. After the feedback seminar the project was regarded as more or less completed. The project group mainly communicated through e-mail when they finished the remaining commitments. Some of them read and commented on the practitioner report that was also submitted in time. Just as R2 concludes when she looks back on the project: 'You can say what you want, but there wasn't one deadline that we didn't hold'. The results from the scientific article were used in the official planning process in the City. The status or use of the practitioner report remains unclear.

\section{Understanding and enacting TD research}

The key interpretation of TD research, developed by the members of Project A, was to deliver high quality results with relevance for research and practice. However, this meaning was not the only one that guided this temporary practice. Of equal important was their ambition to work effectively and deliver on schedule, with all that this entailed. The project leaders stressed the importance of efficiency. R2 appropriated this ambition, and these three together appear to have had a dominant influence over how a TD approach was enacted in this project.

To ensure the objectives of the TD approach, the project members decided to carry out two separate analyses. Their ambition was to work together through all phases of the project. It proved easy to work together during the design and data collection phase. In the analysis and writing phase, when the tasks became more complex and cooperation entailed time-consuming challenges, the researchers fell back to their accustomed roles. Even if "working together" was included in the plan of how to realize transdisciplinarity, it did not constitute a prioritized aspect of the meaning given to the practice. 
Keeping the timetable, on the other hand, was a more foundational aspect of their practice. This was confirmed in that the division of labor that took over after the data collection was completed was never questioned or discussed (it "just happened").

The scientific article illustrated five approaches to sustainable development that were evident in the workshop material. This turned out to interest many of the practitioners invited to the final seminar, while the practitioner report was less well received. These signals, however, did not affect the project group. They re-created (or "stuck") to the initial meaning they gave the TD approach - namely to have an effective process and produce high quality results through two separate analysis.

\section{Reflecting upon the usability of the project results}

According to our interviews, Project A did not create any explicit forums for discussing how the workshops and the project results related to the members' regular practice. Such discussions did not occur spontaneously during the project either. For example, the members did not take the time to reflect upon if, and if so how, they could make use of the positive comments on the scientific paper from the practitioners during the final seminar for the practitioner report. The focus was on completing the project within the deadline and ensuring they followed the original plan. R3 reflected upon this after the project was completed: "... what would have happened if we had written the results more together, had time and the ability to do so. Especially when I look at the results of the scientific article ... where you can see that these strategies, they're quite visual and practical results as well". The temporary practice that the members constructed does not appear to have allowed (let alone encouraged) reasoning and reflections outside of the agenda. The concluding work on the project was done individually, mainly through email. From a temporal perspective this was an effective approach, but hardly one that encouraged the members to reflect upon the experience they shared in the project.

P1 (the only practitioner who was present at the end of the project) says that the individuals participating in the workshops probably gained new insights regarding climate adaptation in urban planning for sustainable development. When asked directly if she got what she hoped when she initiated the project, she replies that she, thanks to the systematic way in which researchers tackled 'her' question, realized that her original question was "perhaps too difficult" and concluded that it after all might not have been possible to find a general model that defines the parameters that she requested. On an individual level, her insights and experiences have enriched her practice. As she is one of the leading City planners working on climate change, this is significant. However, this is nothing that the project paid attention to or brought up in the project results.

\section{Project B - a project characterized by the domination of one perspective}

The idea for Project B came from the Central City Office. As a member of the TD platform, the City saw opportunities to develop new ideas to address the severe problems of social and economic segregation that characterize some of the suburbs in the City. A civil servant from the Central City Office was given the responsibility to invite a broad group of researchers and practitioners to discuss and formulate a pilot project dealing with social segregation. The initial goal of this project was to build upon the different on-going City projects and link them to a newly established branch of the City University in one of the Northern suburbs, here called 'Suburb'.

One of the invited researchers took the lead in forming the initial project plan. He was later chosen to be one of the project leaders (R1). The other project leader (P1) was a civil servant from the Social Resource Administration, who had practical experiences with working with citizen involvement in segregated areas. Since the City was specific in their wish to both build upon their years of working with this issue and to have substantive local expertise in the working group, four additional 
practitioners were selected for the project working group: a lecturer in social work from the City University (P2); the civil servant at the Central City Office who initiated the project (P3); a civil servant from the Public Property Office at the City (P4); and a civil servant from the Social Resource Administration (P5). One additional researcher, R2, also from the City University was selected at the initiative of R1. According to the preliminary project plan by R1, the project would be docked into a number of activities that were to be included in the University courses that were located to the Suburb. These activities were to take place in the Suburb during the project period and focused on engaging the citizens. By being part of these activities, Project B would learn about citizen participation, capacity building and empowerment.

During the first day of the kickoff meeting, R1 described in detail the events that would take place in the Suburb (reconstruction of public spaces and small scale business establishments), the role of the university courses in these events, and in what way they also could be useful for the project. In addition to these activities, the courses would include workshops and lectures by international experts on civic engagement and capacity building that could be of interest for the project. The second day of the kickoff was devoted to discussing the project plan. The group members brought up questions such as how the work could be organized to ensure that the knowledge generated was meaningful and of benefit for the City (P1, P3, P4); the importance of delimiting the project empirically to a manageable numbers of activities (R2); and the need for formulating clear research questions and methods (R2). These concerns were toned down by R1, who argued that: “... we should rather focus on some questions based on several different activities than select a few specific activities" and: "I want the process to be open in the beginning". No one questioned these suggestions. The kickoff ended without the group having shared and discussed their different expectations and assumptions about what the project could and should achieve. No decisions were made, except the date when the group would meet again to continue the discussion and develop a detailed action plan and timetable for the project.

At the beginning of the project, the project leader, P1, moved to another workplace, and could not engage in the project as actively as was initially planned. However, she remained the formal project leader. P2, the senior lecturer who worked with courses located at the Suburb, became an informal project leader, as she and R1 were the ones who had daily contact and the only ones who had insights into the activities and events that took place in the Suburb.

The project continued to be open with respect to how to interpret TD and what empirical activities to include. Despite this the members started to collect data. They observed and documented a number of participatory activities that took place in the Suburb. As the project progressed, more and more activities "with relevance for the project" (R1) were included. Some of the events were derived from the ordinary work of the Social Resource Administration and the Public Property Office. Others were introduced by the University courses that R1 and P2 were responsible for. Parallel to this data collection, the project had meetings every three weeks where the members evaluated and exchanged experiences, discussed the next steps and concepts like TD, learning and capacity building.

The members were initially “... enthusiastic about doing things together" (P1). The regular meetings were experienced as interesting and worthwhile (R1 and P1). However, over time some of the project members began to feel doubtful. They felt unsure about their roles (P4, P5, R2), the relevance of what they were doing (P4) and missed a clear structure and delineation of the project (P3). In spite of the "high ceilings" (P1) in the group, no one brought up these problems to discussion but trusted R1 and P2 to lead the work. R2 for instance notes that she always felt peripheral because of her feeling of ignorance of what happened in the project, which simultaneously prevented her from questioning the 
agenda of R1 and P2: "It is pretty obvious to me that it is $R 1$ and $P 2$ who have formed the project and I have not seen any reason to challenge that".

During the project period, the members also discovered the different starting points and expectations they had on the project. The initial project plan focused on an important area of interest of the City, namely to develop more in depth understanding about citizen involvement and how to design participatory processes to support citizens in overcoming social and economic segregation. But in an interview with R1, the researcher behind the plan, it becomes clear that he had more transformative expectations on the project. From his perspective, the reasons why the City had not already come to grips with problems related to segregation were the bureaucratic and hierarchic structures of the City Administration as well as the attitude of the officials. He hoped that the project would inspire more fundamental changes in the City Administration Offices.

During the project, the three officials P1, P3 and P4 explain that they gradually understood that R1 and P2 represented a perspective that was based on a picture of the City Administration as a sluggish organization that stops all initiatives coming from citizens. P3 notes, for example, that during the project meetings there was sometimes a tone of that: "We, the civil servants, somehow automatically are those who do not want to have contact with residents ", and: “... there is an idea that: 'Politicians do not want, and civil servants do not dare'. I do not recognize myself in that reality". R1 never mentions these disagreements during the interviews. He points out that the project was stressful and intense, that there was too little time for reflection because of this.

\section{Understanding and enacting TD research}

The members of Project B never created a discernible joint meaning around what a TD approach entailed for them. The enactment of TD research according to the interviews focused on the process in the project group, for example by emphasizing the importance of using democratic meeting methods, in the regular group meetings, but not on the project design, activities, collection of data, or analysis of results. The attempts by some of the members to sharpen and define the project in the kickoff was averted by R1, who argued that the project would benefit from being open to most things that went on in the Suburb. His view of TD research was that it was open and bottom-up, more related to how they interacted in the project group and in opposition to the closed and top steered approaches in traditional research. Nevertheless, the project became top steered. Because of the constant addition of new activities, all but R1 (and possibly P2) soon lost the ability to overview and control the project. This lack of transparency and oversight excluded and disadvantaged the other project members. Because they lacked insights about the project, they also lacked legitimacy to take initiative and question the project. Their experiences were thus not included in the considerations and decisions that were made regarding how the project should be carried out and what it should focus on.

While Project B had no common understanding of how TD should be enacted, based on the theory of situated learning, they still created a shared practice. The meaning of this practice included not having any shared meaning regarding what the project should accomplish and why, to let R1 (and P2) control and operate the project, and also to let R1 (and P2) take responsibility for the project completion. The other members' roles as co-creators of the project were not to question. According to the theory of situated learning, we are not only given a role and an identity in the practices we belong to, we "take" them by the way we respond to what is "given" us. A non-response is also a response and a contribution to the co-creation of a practice and the roles of its members. 
Overall, the project leadership, both formal and informal, did not seem to understand how their position excluded and pacified the other members of the project group. The most important conclusions drawn from the leadership was that the funding was inadequate, that for the project to be successful the members should have been given much more time and resources.

\section{Reflecting upon the usability of the project results}

We can easily imagine that R1's critical outsider perspective on the officials and their organizations together with the officials' own experiences and insider perspectives could have greatly enriched each other. They could have gained profound and reflected insights into the city's work on social segregation, and what kind of strategies might better contribute to empowerment and capacity building among citizens of the suburb. However, the discussions held during the meetings did not lead to insights of this kind. Since R1 and P2 took, and were given, the lead, it was from their perspective that the project viewed the participatory activities, and considered the city's "inability" to deal with the effects of segregation in the suburb. The officials' previous experience of participatory processes, as well as their experiences of being officials, was not used in the project. The two perspectives did not enrich each other because of the dominance of one over the other. The officials in the project thus did not express learning things from the project that they found to be relevant for their work with social segregation. All of the three officials conclude that the project only reinforced what they already knew. P1, for example said: "We had similar results from other experiences, though they were not from a research project." And P3 notes that the project would have been more valuable if multiple perspectives had been included throughout the project: "...there was a strong focus on Rls research perspective.... and I don't question that, but it could have been complemented". According to the officials, this lack of interest, respect and recognition for their insider perspective on the City Administration lasted throughout the project period.

Additionally, and unlike Project A, Project B explicitly created spaces for collective reflection on the documentation of events and activities in the project. The group met and discussed their experiences and reflections every three weeks. The project members thus created a forum for reflection, however these reflections did not start out from or even include the experiences and perspectives of the practitioners in ways that were meaningful for them in relation to their ordinary practice. Therefore, the kind of reflection that is a precondition for knowledge transformation between practices, from a situated learning perspective, was not enabled in the temporary practice created by the members of Project B.

\section{Project $\mathrm{C}$ - a project characterized by an interest in practitioners' experiences}

The complexity of sustainable urban development is a great challenge for local and regional policy making and management. To meet these challenges, the City where the TD Platform is located, had recently implemented a number of innovative multi-level and cross-sector governance processes for sustainable urban development. Three of these processes focused on future transport needs, social polarity and sustainable economic development, respectively. They included interactions between political and civil servant spheres at different levels of public policy and management. Their objective was to transform ideas into policies, goals and actions. The overall aim of Project $\mathrm{C}$ was to collect and build upon the experiences from these collaborative processes. This project was initiated and supported by three of the TD-Platform partners working with such planning challenges, including the City Region Association of Local Authorities (RALA), the City and the Regional Political Body (RPB). 
A practitioner at RALA (P2), who had been active in one of the cross-sector governance processes under study, initiated the project. He took the overall responsibility for calling the meetings and writing the initial project plan, which was used as the starting point for staffing and designing the project. He also suggested a project leader (P1) who had been working with different political processes in the local area and also had a research background from the City University to be one of the co-leaders. The other project team members were chosen among practitioners who had been active in the three consultative processes under study. These included two officials from the City Office (P3, P6), one from the Road Administration, (P4); and one from RPB (P5). The second project leader, a Professor from the City University with a background in social science (R1), was chosen at the end of the initial phase. One additional researcher was added to the project team (R2) from another university, whose research focus fitted well with the project. Project $\mathrm{C}$ was thus organized around a tight working group consisting of TD Platform representatives, with first-hand experience of the processes under study, and two social science researchers.

Overall, this project grew out of practitioner's interest to evaluate the three governance processes in depth to better understand how such processes can be designed and contribute to complex societal challenges. The researchers did not have any objections, but thought that the idea was relevant. According to our interviews, the one day project kick-off enabled the project group to discuss and create shared understanding of what the project should accomplish and why. R1, who was not involved in the initiation of the project, and was unfamiliar with the City governance processes, notes that the group had completed a "very good project proposal" which made it convenient for her to get an overview of the project idea and "just ease into" the work.

To get multiple perspectives on the three governance processes chosen as study cases, the group reassembled the politicians and civil servants who had taken part in the processes into three workshops (one for each of the process). Each workshop collected from 20 to 30 stakeholders who met in plenary as well as small focus groups. The project leaders handed over the major responsibility for this work to the practitioners in the team, which was greatly appreciated: "The last thing we wanted to be was a reference group. We became the organizers. We made lists, decided who were relevant to invite [to the workshops], it felt good to be involved ... we examined the processes based on our battery of questions. And this, I think, was rigorous work" (P3).

After each workshop, the group met for one day to discuss the governance processes from as many angles as possible and reflect upon the implications of the material collected as well as their discussions. These meetings were recorded and transcribed. Initially the group had no clear idea about how to carry out their analysis. To create a structure for their work, the project leaders (P1, R1) and R2 started to write summaries of the discussions taking place during these meetings including suggesting tentative theoretical concepts of and explanations to phenomena that the team had identified. According to the practitioners, these texts and concepts were valuable and encouraged reflection, not the least because the researchers emphasized that they had no answers but rather questions on whether the suggested concepts could contribute to their joint understanding.

The officials showed little interest in taking active part in writing the policy report, despite the encouragement from the project leaders. Instead they preferred to read and verbally comment on the drafts compiled by R1, P1 and R2. This, the practitioners explain, was partly due to their general lack of time (P4, P5). However they also emphasize that they saw no reason to contribute to the writing as they realized the researchers readiness to incorporate their experiences and perspectives, as well as their sensitivity in describing the joint understanding that the analysis phase of the project resulted in 
(P2, P3, P4, P5). The project resulted in a co-authored policy report, by all members of the project group, and a number of scientific articles, by the researchers.

\section{Understanding and enacting TD research}

The overall meaning of the temporary practice created by the members of Project $\mathrm{C}$, was to develop joint understanding of multi-level and cross sector governance based both on the practitioners' experiences of the three governance processes and on theoretical insights provided by the researchers. While the members of project $\mathrm{C}$ rarely use the word "transdisciplinary", they organized their task based on a shared aspiration of gaining in-depth and critical understanding of the processes under study and placing them in a wider context. The group, including the project leaders, didn't have any preconceptions about how the project should be done or what the results would be. The members tried their way, and in so doing they created the overall meaning of the practice (to develop critical understanding) in the way they participated and interacted throughout the project. The organization of this practice implied that the practitioners were given (and took) responsibility for the data collection. Since they themselves could read the transcripts of their project meetings, the practitioners saw their perceptions through the lenses of theories and concepts suggested by the researchers. They were therefore deeply involved in the analysis in the project. Though they weren't involved in writing, the practitioners felt that they contributed equally to the analysis of the workshop material and the formulation of the results.

The way the project was organized and the members contributed to enacting TD research created a confident and open atmosphere (in fact the word used most often in the interviews to describe this project is 'open'). It is important to note that this openness and trust in the group was not based on them having similar opinions and backgrounds. They together created a practice that dealt constructively with multiple and sometimes conflicting perspectives. The openness and trust that characterized this practice can (based on situated learning) also be seen as norms regarding how to handle different and conflicting opinions within the temporary practice. Such norms are important in a practice that is guided by the overall goal of creating joint understandings. To reach such understandings, contradicting and conflicting views cannot be rejected; they must be appreciated and subjected to joint, critical inquiry (Bechky 2003, Hallgren \& Westberg 2015).

\section{Reflecting upon the usability of the project results}

Since Project $\mathrm{C}$ was not only initiated, but also driven to a great extent by the interests of the participating practitioners, there was an implicit focus on how the results could make sense outside the temporary TD practice. In the interview with the team right after the project was completed, the members note that the project had given them new, more critical perspectives on multi-level and cross sector governance processes and what needs to be paid attention to, to ensure the desired learning, that they will benefit from and take advantages of in future processes: "It would have been interesting to have a well defined process in the other direction as well. I mean to apply our experiences when specifying an order [of a governance process]. But I guess we had if we had had more time." As a result of the analysis, a number of important factors for successful collaboration and learning in governance processes were identified in the policy report.

The practitioners noted repeatedly that they learned a lot from this project that could be used in their ordinary practices: "Every time we met, I feel like I learned something new, but it isn't easy to put words on it" and "I can definitely use what I learned in this project in my work, it's just not easy to put it down on an A4 paper". Even if there, according to the interviews was no time for explicitly reflecting on the usability of the insights and results, the way that the practitioners participated in the 
project and influenced its form and content, made it relevant for them in their ordinary practices.

\section{Discussion and conclusions}

The overall purpose of this article was to test if the theory of situated learning can help us to better understand learning and knowing in TD research processes, as well as to to understand the ability of such processes to contribute to societal change. According to the analysis presented here, this is indeed the case. A practice-based approach to learning greatly increased our ability to understand the knowledge exchanges and knowing that occurs in the TD research projects studied here. By focusing on 'TD practice', or how the project groups enacted their version of TD research, through both what they said and did, we gained a more in-depth understanding of the challenges and opportunities of TD research. By focusing on how the projects enabled reflection on the usability of the project results, we gained crucial insights into why some TD research projects do not live up to their expectations or assumptions of their ability to create socially robust and/or usable results. Both of these insights have important implications for TD practice and research.

The theory of situated learning posits that learning is a genuinely social phenomenon, taking place as individuals participate in practices. Individuals learn by participating in the creation of the meanings of their practices and in contributing to the fulfillment of these meanings. Because of the way learning is understood, situated learning theory also posits that learning and knowledge developed in one practice cannot be easily "transferred" to another; they have to instead be "translated" to make sense in different contexts. Starting from this theory, we have shown how the members of the three TD projects, based on how they interpreted the instructions and the conditions and resources available, learned to participate and contributed to enacting the meaning of TD research that they themselves created. This is why the three projects developed in different ways despite the fact they had been given the same instructions, and equal amounts of time, money and support. Project A was guided by ideas emphasizing efficiency in their interpretation of what should be achieved, and Project B's interpretation of this task was dominated by the views of one participant. None of these projects enabled the space for meta-learning and reflection that, according to situated learning theorists, is necessary for the emerging understanding to move between practices. This is why there are reasons to assume that however meaningful what is learned by participating in the projects might seem, much of what is learned is difficult to apply outside of the temporary TD practices that are created.

Only one of the projects, Project $\mathrm{C}$, organized their practice in a way that enabled the type of learning that was experienced as highly relevant for the practitioners in their ordinary practices. Rather than focusing on delivering project reports and articles, the meaning that the members created around this TD practice focused on developing joint understandings that were based on their different perspectives of the governance processes under study. In contrast to the other two projects, Project $\mathrm{C}$ rarely discussed what they were doing in terms of transdisciplinary research. They instead focused on creating joint understandings. This focus resulted in the practitioners becoming deeply involved in and contributing to the analysis. It enabled all of the project members to critically reflect upon their own, as well as others' perspectives. According to the participating practitioners, this way of working together generated insights that were useful in their everyday work practices.

Overall, the main lessons learned from this study have both practical and research implications. As noted by way of introduction, knowledge exchange between diverse actor groups is central to its ability to produce usable results. When it comes to practical issues regarding how to design and enact TD research processes, it is first important to identify not only what 'joint understandings' entail in 
such practices, but also how the project members can actively design spaces for those involved to (with help of facilitation if necessary) regularly and self-reflexively interact from a 'pluralist understanding of cognition and interpretation of the world' (Pohl et al 2010: 279). This later point is important when different types of scientific and practitioner-based knowledge interact, especially given the sometimes different status of such knowledge sources, to avoid one perspective or understanding being seen as more relevant or legitimate than others. Second, it is critical to continually, throughout the TD project, explicitly discuss the relevance and usefulness of project activities, outcomes and learning in relation to the ordinary practices of the practitioners. Such explicit and consistent attention to both what learning entails in such processes, as they occur, and to the usability of the knowledge created function to keep the projects on track, and can hopefully contribute to avoid the main pitfalls of TD research identified in the cases analyzed here.

The view on knowing and learning as situated is highly relevant when it comes to research and how to analyze, theorize and evaluate the learning and joint knowledge production in TD processes. Terms such as "up scaling", "scalability" and "actionable" knowledge all suggest a transferability of learning and knowledge that is based on a deeply rooted misconception of knowledge as neutral and context independent (Nicolini et al 2003, Talwar et al 2011, Lang et al 2012, Wiek et al 2012, Wiek et al 2014). Situated learning contributes with an in-depth explanation of why it is difficult to re-integrate seemingly "socially robust" results generated in TD projects into the ordinary practices of those who generated them. It's not just time demanding, insufficient participation, lack of institutional support and communication barriers, as many research studies show (Blackstock \& Carter 2007, Lang et al 2012, Stokols et al 2008, Talwar et al 2011, Robinson 2008). The barriers to TD research are deeper than so.

Our study shows that a practice-based perspective increases our understanding of what the creation of socially robust knowledge entails in actuality, and what this implies for its ability to contribute to societal change. The TD process itself creates knowledge that cannot be transferred into other contexts, because and as this study exemplifies, it is situated in a specific TD practice. "Socially robust" is a normative term that is rarely defined or problematized. In the analysis presented here, socially robust knowledge is context dependent, not only in the sense of a certain geographical time or place. Socially robust knowledge is also dependent upon the micro-context in which it is enacted and produced, within its practice. The focus in the TD discourse, on creating generalizable knowledge, or knowledge that is exchangeable between different contexts in this sense is therefore highly problematic.

It is therefore time to scrutinize the assumptions that are currently guiding many TD research approaches, namely the normative and instrumental use of learning. As noted by way of introduction, many TD research studies assume that learning automatically results in certain desired outcomes and that knowledge is unproblematically transferable between projects and contexts. Practice based approaches, like the one applied in this study, give us better analytical tools to understand and analyze how knowledge exchanges occur between practitioners and researchers. Such approaches and their resultant insights are essential if we are to correctly identify and address the challenges facing TD research and its ability to contribute to create socially robust knowledge and contribute to societal change.

\section{References}


Bechky BA (2003) Sharing Meaning Across Occupational Communities: The Transformation of Understanding on a Production Floor. Organization Science 14 (3): 312-330

Bergmann M, Jahn T, Knobloch T, Krohn W, Pohl C, Schramm E (2012) Methods for Transdisciplinary Research: A Primer for Practice. Campus Verlag, Frankfurt

Blackstock KL, Carter CE (2007) Operationalizing sustainability science for a sustainability directive? Reflecting on three pilot projects. Georgr J 173 (4): 343-357

Brown JS, Duguid P (2001) Knowledge and Organization: A Social-Practice Perspective. Organization Science 12 (2): 198-213

Carlile PR (2002) A Pragmatic View on Knowledge and Boundaries: Boundary Objects in New Product Development. Organization Science 13 (4): 442-455

Chaiklin S, Lave J (eds.) (1993) Understanding practice: Perspectives on activity and context. Cambridge University Press, Cambridge

Contu A (2014) On boundaries and difference: Communities of practice and power relations in creative world. Management Learning 45 (3): 289-316

Contu A, Willmott H (2003) Re-Embedding Situatedness: The Importance of Power Relations in Learning Theory. Organization Science 14 (3): 283-296

Crang M, Cook I (2007) Doing ethnographies. Sage.

Engeström Y, Middleton D (eds.) (1996) Cognition and Communication at Work. Cambridge University Press, Cambridge

Gibbons M, Limoges C, Nowotny H, Schwartzman S, Scott P, Trow M (1994) The new production of knowledge: The dynamics of science and research in contemporary society. Sage Publications, London

Gherardi S (2001) From organizational learning to practice based knowing. Human Relations 54 (1):131-139

Gherardi S, Nicolini D (2003) To Transfer is to Transform: The Circulation of Safety Knowledge. In: Nicolini D, Gherardi S, Yanow D (eds.) Knowing in Organizations, a Practice-Based Approach, M.E Sharpe, London, pp 204-224

Hallgren L, Westberg L (2015) Adaptive management? Observations on the role of understandingorientated communication practice in wildlife management. Wild Life Biology 21 (3): 165-174.

Heizmann H (2011) Knowledge sharing in a dispersed network of HR practice: Zooming in on power/knowledge struggles. Management Learning 42 (4): 379-393

Hellström T (2015) Formative evaluation at a transdisciplinary research center in Polk M (ed) Coproducing knowledge for sustainable cities: Joining forces for change. (pp 146-165). Routledge, London 
Hotho J, Saka-Helmhout A, Becker-Ritterspach F (2014) Bringing context and structure back into situated learning. Management Learning (1): 57-80

Hughes $\mathbf{J}$ (2007) Lost in translation: communities of practice. The journey from academic model to practitioner tool. In: Hughes J, Jewson, N, Unwin L (eds.) (2007) Communities of Practice, Critical Perspectives. Routledge, New York pp 30-40

Hughes J, Jewson, N, Unwin L (eds.) (2007) Communities of Practice, Critical Perspectives. Routledge, New York

Jahn T, Keil F (2015) An actor-specific guideline for quality assurance in transdisciplinary research. Futures 65: 195-208

Kates RW, Parris TM, Leiserowitz AA (2005) What is sustainble development: goals, indicators, values and practice. Environment 47 (3): 8-21

Lang DJ, Wiek A, Bergmann M, Stauffacher M, Martens P, Moll P, Swilling M, Thomas CJ (2012) Transdisciplinary research in sustainability science: practice, principles and challenges. Sustain Sci 7 (Supplement 1):25-43

Lave J, Wenger E (1991) Situated learning Legitimate peripheral participation. Cambridge University Press, Cambridge

Miller TR, Wiek A, Sarewitz D, Robinson J, Olsson L, Kriebel D, Loorback D (2014) The future of sustainability science: a solutions-oriented research agenda. Sustainability Science 9: 239-246

Nicolini D (2012) Practice Theory, Work, \& Organization, an introduction. Oxford University Press, Oxford.

Nicolini D, Gherardi S, Yanow D (2003) Introduction: towards a Practice-Based view of Knowing and Learning in Organizations. In: Nicolini D, Gherardi S, Yanow D (eds.) Knowing in Organizations, a Practice-Based Approach, M.E Sharpe, London, pp 3-31

Nowotny H, Scott P, Gibbons M (2001) Re-thinking Science: Knowledge and the public in an age of uncertainty. Polity Press, Cambridge

Pohl C (2007) From science to policy through transdisciplinary research. Environmental Science and Policy 11:46-53

Pohl C, Hirsch Hadorn G (2007) Principles for Designing Transdisciplinary Research. Oekom, Munich

Pohl C, Rist S, Zimmermann A, Fry P, Gurung GS, Schneider F, Speranza CI, Kiteme B, Boillat S, Serrano E, Hirsch Hadorn G, Wiesmann U (2010) Researchers roles in knowledge co-production: experience from sustainability research in Kenya, Switzerland, Bolivia and Nepal. Science and Public Policy 37(4): 267-28

Polk M (2014) Achieving the promise of transdisciplinarity: a critical exploration of the relationship between transdisciplinarity research and societal problem solving. Sustainability Science 9: 439-451

Polk M (2015) Transdisciplinary co-production: Designing and testing a transdisciplinary research framework for societal problem solving. Futures 65: 110-122 
Popa F, Guillermin M, Dedeurwaerdere T (2015) A pragmatist approach to transdisciplinarity in sustainability research: From complex systems theory to reflexive science. Futures 65: 45-56

Robinson J (2008) Being undisciplined: transgressions and intersections in academia and beyond. Futures 40: 70-86

Schauppenlehner-Kloyber E, Penker M (2015) Managing group processes in transdisciplinary future studies: How to facilitate social learning and capacity building for self-organised action towards sustainable urban development? Futures 65: 57-71

Scholz RW Steiner G (2015a) The real type and ideal type of transdisciplinary processes: part I theoretical foundations. Futures 10: 527-544

Scholz RW Steiner G (2015b) The real type and ideal type of transdisciplinary processes: part II what constraints and obstacle do we meet in practice? Futures 10: 653-671

Stokols D,Hall KL, Moser MP, Feng, A,Misra S, Taylor BK (2010) Cross-disciplinary team science initiatives: Research, training, and translation. In: Frodeman R (ed) The Oxford handbook of interdisciplinarity, Oxford University Press, Oxford, pp 471-493

Swan J, Scarbrough H, Newell S (2010) Why don't (or do) organizations learn from projects? Management Learning 41 (3): 325-344

Talwar S, Wiek A, Robinson J (2011) User engagement in sustainability research. Science and Public Policy 38 (5):379-390

Wenger E (1998) Communities of practice. Learning, Meaning and Identity. Cambridge University press, Cambridge

Wertsch JV (1991) Voices of the Mind: Sociocultural Approach to Mediated Action. Harvard University Press, Harvard

Westberg L, Powell S (2015) Participate for women's sake? - A gender analysis of Swedish deliberative NRM projects. Society and Natural Recourses DOI: 10.1080/08941920.2015.1014594

Whittmayer JM, Schäpke N (2014) Action, research and participation: roles of researchers in sustainability transitions. Sustainability Science 9: 483-496

Wiek A, Withycombe L, Redman CL (2011) Key competencies in sustainability: a reference framework for academic program development. Sustainability Science 6: 203-218

Wiek A, Ness B, Schweizer-Ries P, Band FS, Farioli F (2012) From complex systems analysis to transformational change: a comparative appraisal of sustainability science projects. Sustain Sci 7 (Supplement 1): 5-24

Wiek A, Talwar S, O'Shea M, Robinson J (2014) Toward a methodological scheme for capturing societal effects of participatory sustainability research. Research Evaluation 23: 117-132

Yanow D (2003) Seeing Organizational Learning: A “Cultural” View. In: Nicolini D, Gherardi S, Yanow D (eds.) Knowing in Organizations, a Practice-Based Approach, M.E Sharpe, London, pp 3352 
